\title{
Self-assembled 1-octadecyl-1H-benzimidazole film on copper surface for corrosion protection
}

\author{
B V APPA RAO* and M NARSIHMA REDDY \\ Department of Chemistry, National Institute of Technology Warangal, Warangal 506004 , India \\ e-mail: boyapativapparao@ rediffmail.com
}

MS received 25 June 2013; revised 20 August 2013; accepted 21 August 2013

\begin{abstract}
Films of 1-octadecyl-1H-benzimidazole (OBI) have been formed on copper surface by selfassembly method. Optimum conditions viz. the solvent, concentration of OBI, immersion period and temperature for the formation of a protective film on copper have been established using impedance studies. The OBI film has been characterized by X-ray photoelectron spectroscopy, reflection absorption Fourier transform infrared (FTIR) spectroscopy, contact angle measurements and atomic force microscopy. Efficiency of the OBI film to protect copper from corrosion has been investigated in aq. $\mathrm{HCl}$ solution using electrochemical impedance spectroscopy, potentiodynamic polarization method, cyclic voltammetry, scanning electron microscopy and gravimetry. Results of these studies inferred that the OBI film has an inhibition efficiency in the range of 97-99\% under different conditions. Polarization studies inferred that the OBI film functions as a cathodic inhibitor. Cyclic voltammetric studies showed that the film is stable even after 15 cycles, when the copper electrode is polarized to an anodic potential of $0.35 \mathrm{~V} v \mathrm{vs} . \mathrm{Ag} / \mathrm{AgCl}$ electrode.
\end{abstract}

Keywords. Copper; benzimidazole; self-assembled film; X-ray photoelectron spectroscopy (XPS); impedance; corrosion protection.

\section{Introduction}

Copper is considered as an alternative material to aluminium and gold in microelectronics packaging. ${ }^{1}$ The advantages of copper are its high electrical and thermal conductivities. Advances in semiconductor manufacturing technology have led to the integration of millions of transistors, each capable of switching at a high speed. A consequence of incorporating so many fast switching transistors into an integrated circuit is an increase in power consumption during operation. One technique for increasing speed while reducing power consumption is to replace the traditional aluminium and aluminium alloy interconnects with copper metal, which offers lower electrical resistance. ${ }^{2}$ However, in contrast to aluminium, copper does not form self-passivating oxide film and readily undergoes corrosion.

Corrosion protection of copper by a film of organic molecules formed by self-assembly method has been reported in literature. ${ }^{3,4}$ Self-assembled films of alkanethiols and Schiff bases have been studied for corrosion protection of copper. ${ }^{5,6}$ However, the toxicity of these molecules limits their application in industry. ${ }^{7}$ Owing to strict environmental regulations, attention is

*For correspondence now focused on the formation of films with molecules of less toxicity.

The objective of the present research is to study the efficiency of corrosion protection of copper by a film of 1-octadeyl-1H-benzimidazole (OBI). The reasons for choosing OBI molecule for the formation of a film are worth mentioning. The imidazole groups are known to be less toxic ${ }^{8}$ and also known to inhibit corrosion of copper. ${ }^{9}$ OBI consists of two nitrogen atoms as active sites for chemisorption and chelation with copper ions to form a protective film on copper surface. The OBI also consists of a long hydrocarbon chain which can make the film hydrophobic. The present study includes the development of optimum conditions for the formation of self-assembled film of OBI and to evaluate its efficiency of corrosion protection in aqueous $\mathrm{HCl}$ solution. The molecular structure of OBI is shown in figure 1.

\section{Experimental}

\subsection{Materials}

OBI was synthesized by mixing equimolar amounts of 1-bromooctadecane, benzimidazole and potassium carbonate in a round bottomed flask in the presence of a 


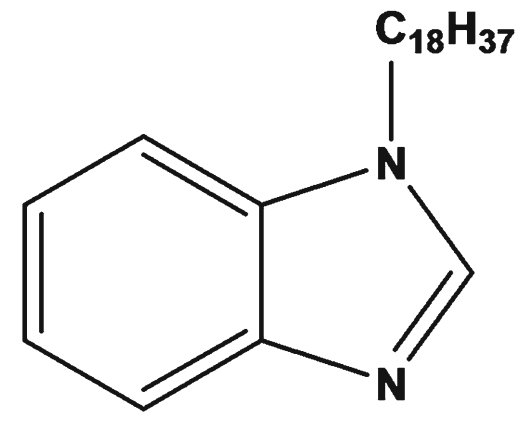

Figure 1. Structure of 1-octadecyl-1H-benzimidazole (OBI).

solvent, N,N-dimethylformamide and then refluxing the contents for $24 \mathrm{~h} .{ }^{10} \mathrm{OBI}$ was then characterized by IR and ${ }^{1} \mathrm{H}$ NMR spectroscopy techniques. All the chemicals were of AR grade and were purchased from either Sigma Aldrich or Qualigens Chemicals, India.

\subsection{Preparation of copper specimens}

Substrates used for sample preparation are of different dimensions for different methods of study and were made from a copper sheet of purity $99.9 \%$. Copper specimens with dimension of $1.0 \times 1.0 \times 0.2 \mathrm{~cm}$ were used in surface analytical studies. Specimens of dimension of $4.0 \times 1.0 \times 0.2 \mathrm{~cm}$ were used in all electrochemical studies and only $1 \mathrm{~cm}^{2}$ area was exposed to the electrolyte, while the remaining area was sealed with epoxy resin. Specimens with dimension of $4.0 \times$ $1.0 \times 0.2 \mathrm{~cm}$ were used in gravimetric studies also. These specimens were polished to mirror finish using $1 / 0,2 / 0,3 / 0,4 / 0$ grades emery paper in the given order and then with fine alumina powder on a rotating disk. Specimens were washed with double distilled water and degreased with acetone. The specimens were again washed with the solvent chosen for formation of OBI film and finally dried with flow of nitrogen gas.

\subsection{Formation of self-assembled film of OBI on copper}

Solubility of OBI was tested in various solvents and it was found that OBI is soluble only in methanol. Therefore, methanol was chosen as the solvent for formation of OBI film on copper surface. Exactly $463 \mathrm{mg}$ of OBI was dissolved in $250 \mathrm{~mL}$ methanol to get a $5.0 \mathrm{mM}$ solution, which corresponds to the solubility limit. Solutions of 1.0 and $3.0 \mathrm{mM}$ were prepared by dilution from 5.0 mM solution. Polished copper specimens were etched with $7 \mathrm{~N}$ nitric acid for $30 \mathrm{~s},{ }^{6}$ washed first with double distilled water and then with methanol. Metal specimens were immediately immersed in different concentrations of OBI solution in methanol for various immersion periods at a constant temperature of $30 \pm 0.1^{\circ} \mathrm{C}$.

\subsection{Electrochemical studies}

Electrochemical studies were carried out using a threeelectrode cell assembly (in accordance with American Society for Testing and Materials (ASTM) specifications) and an electrochemical work station model IM6e ZAHNER Elektrik, Germany. Experimental data were analysed using THALES software. Bare copper or OBImodified copper electrode was used as working electrode. Pt foil was used as counter electrode and reference electrode was $\mathrm{Ag} / \mathrm{AgCl}(3 \mathrm{M} \mathrm{KCl})$. The cell was open to air and all experiments were conducted at a constant temperature of $30 \pm 0.1^{\circ} \mathrm{C}$.

2.4a Electrochemical impedance studies: Electrochemical impedance studies (EIS) were carried out at open circuit potential in the frequency range of $60 \mathrm{kHz}$ to $10 \mathrm{mHz}$ with a sinusoidal potential perturbation of $\pm 5 \mathrm{mV}$ in amplitude. Impedance studies were first carried out in order to develop optimum conditions for the formation of a protective film on copper surface. These studies were also carried out in order to evaluate the corrosion protection ability of OBI film in an aggressive environment viz. aq. $\mathrm{HCl}$ at different concentrations $(0.02-0.20 \mathrm{M})$ and at various immersion periods (1-24h).

2.4b Potentiodynamic polarization studies: Potentiodynamic polarization studies were performed in the potential range of $-0.700 \mathrm{~V}$ to $+0.700 \mathrm{~V}$ vs. $\mathrm{Ag} / \mathrm{AgCl}$ $(3 \mathrm{M} \mathrm{KCl})$ at a scan rate of $2 \mathrm{mV} \mathrm{s}^{-1}$. These studies were carried out at different concentrations $(0.02-0.20 \mathrm{M})$ of aqueous $\mathrm{HCl}$ environment.

2.4c Cyclic voltammetric studies: Cyclic voltammetric studies (CV) were carried out in $0.02 \mathrm{M} \mathrm{HCl}$ in the potential range of -0.400 to $+0.350 \mathrm{~V}$ vs. $\mathrm{Ag} / \mathrm{AgCl}(3 \mathrm{M} \mathrm{KCl})$ at three different sweep rates of 30 , 60 and $120 \mathrm{mV} \mathrm{s}^{-1}$ for two cycles at each sweep rate. $\mathrm{CV}$ experiments were also carried out for 15 cycles at a constant sweep rate of $30 \mathrm{mV} \mathrm{s}^{-1}$ in the same potential range in order to study the stability of the OBI film. 


\subsection{Gravimetric measurements}

Bare copper and copper specimens modified with OBI film were immersed in $0.02 \mathrm{M} \mathrm{HCl}$ solution for 10 days. Weights of the specimens before and after immersion were recorded with accuracy in weighing up to $0.01 \mathrm{mg}$. Studies were carried out in duplicate. From the weightloss data, corrosion rates and inhibition efficiencies were calculated. Relative standard error in corrosion rate determination is of the order of $2 \%$ or less. ${ }^{11}$

\subsection{Surface characterization studies}

2.6a X-ray photoelectron spectral studies: X-ray photoelectron spectral (XPS) studies of the bare copper and copper coated with OBI film were carried out using $\mathrm{X}$-ray photoelectron spectrometer, ESCA Kratos model AXIS-165, with $\mathrm{Mg} \mathrm{K} \alpha$ radiation (1253.6 eV) and sensitivity of $0.1 \mathrm{eV}$. Computer deconvolution was applied to identify elemental peaks of copper, oxygen, nitrogen and carbon present in the film.

2.6b Reflection absorption FTIR spectral studies: Reflection absorption FTIR spectra for bare copper and copper coated with OBI film were recorded in single reflection mode using FTIR spectrometer, Perkin Elmer model Spectrum 100S in the spectral range of 400$4000 \mathrm{~cm}^{-1}$ with a resolution of $4 \mathrm{~cm}^{-1}$. Bare copper and copper coated with OBI film were mounted on the reflection accessory and plane polarized light was incident at a grazing angle of $80^{\circ}$ from the surface normal. The sample compartment was continuously purged with nitrogen during the measurement.

2.6c Contact angle measurements: Contact angle measurements for bare copper and for copper coated with OBI film were made by sessile water drop method using a contact angle measuring system, model G10, Kruss, Germany.

2.6d Atomic force microscopy studies: Veeco Nanoscope IV multimode AFM was used to study surface morphologies of bare copper and copper coated with OBI film. Atomic force microscopy (AFM) was used in contact mode between a silicon nitride tip attached to a micro cantilever and the surface of the sample.

2.6e Scanning electron microscopic studies: Scanning electron microscopic (SEM) studies for bare copper and copper coated with OBI film were carried out after immersing the specimens in $0.02 \mathrm{M} \mathrm{HCl}$ environment for a period of 10 days. These studies were carried out by using TESCAN VEGA 3 scanning electron microscope.

\section{Results and discussion}

\subsection{Optimum conditions for formation of OBI film}

3.1a Effect of concentration of OBI: Quan et al. studied the formation of a film of Schiff base on copper surface by self-assembly. ${ }^{6}$ They reported that the optimum concentration of the molecule and immersion time were $5 \mathrm{mM}$ and more than $20 \mathrm{~h}$, respectively, in order to obtain a protective film. Our results showed that an immersion period of $48 \mathrm{~h}$ facilitated formation of a protective film. Therefore, in the present study, an immersion period of $48 \mathrm{~h}$ was first chosen and OBI films were formed on copper surface at various concentrations of $\mathrm{OBI}$ in the range of $1-5 \mathrm{mM}$. Impedance studies of copper coated with OBI film were carried out in aq. $300 \mathrm{ppm}$ chloride environment. Figure 2(a)
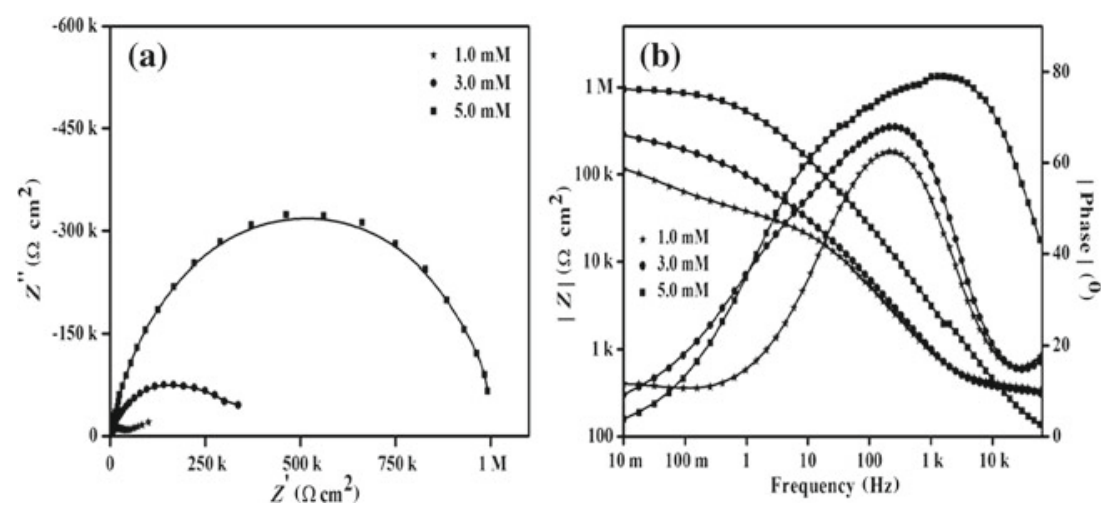

Figure 2. (a) Nyquist and (b) Bode plots of copper coated with OBI film formed at different concentrations of OBI. (Environment: aq. $300 \mathrm{ppm}$ chloride, temperature: $30 \pm 0.1^{\circ} \mathrm{C}$.) 
(a)

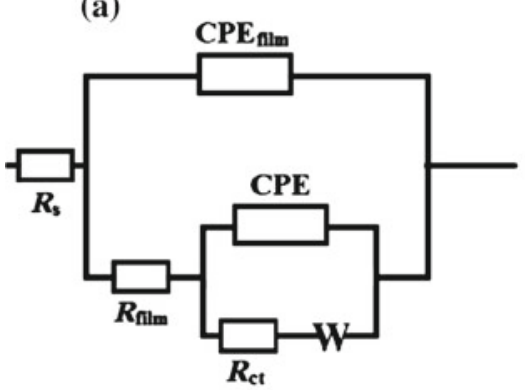

$R_{\mathrm{ct}}$ Charge transfer resistance

CPE Constant phase element

W Warburg impedance (b)
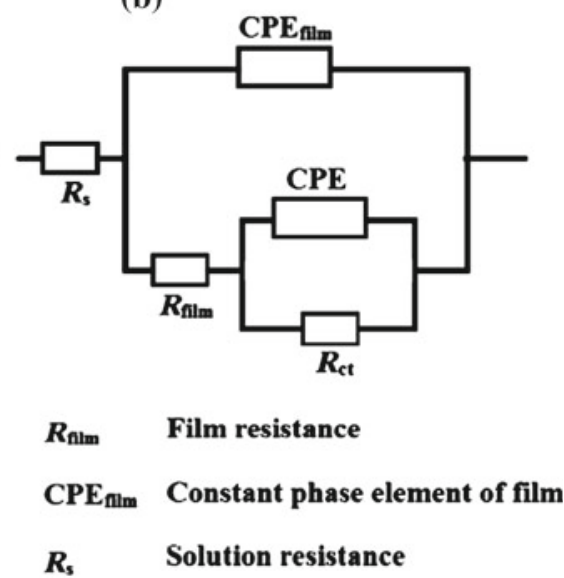

Figure 3. Equivalent circuits used in impedance measurements of (a) copper coated with OBI film with Warburg and (b) copper coated with OBI film.

and (b) shows Nyquist and Bode plots of copper electrode coated with OBI film. Warburg impedance in the Nyquist plots disappeared in the case of copper coated with film from $5 \mathrm{mM}$ concentration of OBI. Phase angle vs. frequency Bode plot showed the highest phase angle maxima followed by broadening in the case of film formed from $5 \mathrm{mM}$ concentration. Corresponding impedance parameters have been obtained by choosing the best fit of the impedance plots using one of the equivalent circuit models shown in figure 3(a) and (b). The circuit shown in figure 3(a) consists of Warburg element and is used in case of copper coated with OBI film showing Warburg impedance in Nyquist plots. Impedance parameters are shown in table 1. With an increase in concentration of OBI from 1 to $5 \mathrm{mM}$, charge transfer resistance $\left(R_{\mathrm{ct}}\right)$ increased from 107.8 to $908 \mathrm{k} \Omega \mathrm{cm}^{2}$, constant phase element $(\mathrm{CPE})$ values decreased from 0.175 to $0.041 \mu \mathrm{F} \mathrm{cm}^{-2}$ and $n$ value increased from 0.81 to 0.90 . High $R_{\mathrm{ct}}$ value at $5 \mathrm{mM}$ concentration reveals that $5 \mathrm{mM}$ concentration of OBI is the optimum concentration for the formation of a protective film.

3.1b Effect of immersion time: Self-assembled films of OBI were formed at different immersion times of copper electrode immersed in $5 \mathrm{mM}$ concentration of
OBI. Nyquist and Bode plots were recorded for copper coated with OBI films and these are shown in figure 4(a) and (b). Corresponding impedance parameters are shown in table 2. Phase angle vs. frequency Bode plot reveals the highest phase angle maximum combined with more broadening in the case of film formed on copper after $48 \mathrm{~h}$ immersion time. Corresponding Nyquist plot also shows the absence of Warburg impedance. The $R_{\mathrm{ct}}$ value increased from 129.8 to $908 \mathrm{k} \Omega \mathrm{cm}^{2}$ with an increase in immersion time from 12 to $48 \mathrm{~h}$. Increase in $R_{\mathrm{ct}}$ value from $36 \mathrm{~h}$ to $48 \mathrm{~h}$ is relatively less. All these results infer that $48 \mathrm{~h}$ immersion period is optimum for formation of a good film.

From all the above studies, it is inferred that optimum conditions for formation of OBI film on copper surface are (i) etching of copper surface in $7 \mathrm{~N} \mathrm{HNO}_{3}$ for $30 \mathrm{~s}$, (ii) methanol as solvent, (iii) $5 \mathrm{mM}$ concentration of OBI, (iv) $48 \mathrm{~h}$ immersion period and (v) $30^{\circ} \mathrm{C}$ temperature. These conditions were used for formation of OBI film on copper surface throughout the studies.

\subsection{Characterization of OBI film on copper}

3.2a Contact angle measurements: Figure 5(a) and (b) shows the contact angle images on bare copper

Table 1. Impedance parameters of copper coated with OBI film formed in different concentrations of OBI. (Environment: aq. $300 \mathrm{ppm}$ chloride, temperature: $30 \pm$ $0.1^{\circ} \mathrm{C}$.)

\begin{tabular}{lcccccc}
\hline $\begin{array}{l}\text { Concentration } \\
\text { of OBI }(\mathrm{mM})\end{array}$ & $\begin{array}{c}R_{\mathrm{ct}} \\
\left(\mathrm{k} \Omega \mathrm{cm}^{2}\right)\end{array}$ & $\begin{array}{c}\mathrm{CPE} \\
\left.(\mu \mathrm{F} \mathrm{cm})^{-2}\right)\end{array}$ & $n$ & $\begin{array}{c}R_{\text {film }} \\
\left(\mathrm{k} \Omega \mathrm{cm}^{2}\right)\end{array}$ & $\begin{array}{c}\mathrm{CPE}_{\text {film }} \\
\left(\mu \mathrm{F} \mathrm{cm}{ }^{-2}\right)\end{array}$ & $n_{\text {film }}$ \\
\hline 1 & 107.8 & 0.175 & 0.81 & 20.83 & 0.035 & 0.26 \\
3 & 314.6 & 0.163 & 0.84 & 25.36 & 0.019 & 0.41 \\
5 & 908.0 & 0.041 & 0.90 & 113.40 & 0.006 & 0.55 \\
\hline
\end{tabular}



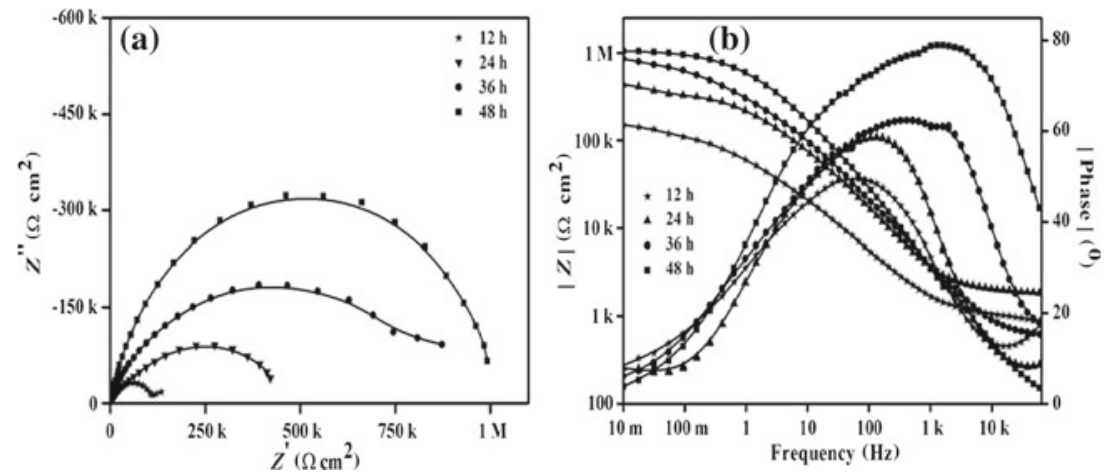

Figure 4. (a) Nyquist and (b) Bode plots of copper coated with OBI film formed in $5 \mathrm{mM}$ OBI at different immersion periods. (Environment: aq. $300 \mathrm{ppm}$ chloride, temperature: $30 \pm 0.1^{\circ} \mathrm{C}$.)

Table 2. Impedance parameters of copper coated with OBI film formed at $5 \mathrm{mM}$ concentration of OBI at different immersion periods. (Environment: aq. 300 ppm chloride, temperature: $30 \pm 0.1^{\circ} \mathrm{C}$.)

\begin{tabular}{lcccrrr}
\hline $\begin{array}{l}\text { Immersion period } \\
\text { for formation of } \\
\text { OBI film (h) }\end{array}$ & $\begin{array}{c}R_{\mathrm{ct}} \\
\left(\mathrm{k} \Omega \mathrm{cm}^{2}\right)\end{array}$ & $\begin{array}{c}\mathrm{CPE} \\
\left(\mu \mathrm{F} \mathrm{cm}{ }^{-2}\right)\end{array}$ & $n$ & $\begin{array}{c}R_{\text {film }} \\
\left(\mathrm{k} \Omega \mathrm{cm}^{2}\right)\end{array}$ & $\begin{array}{c}\mathrm{CPE}_{\text {film }} \\
\left(\mu \mathrm{F} \mathrm{cm}^{-2}\right)\end{array}$ & $n_{\text {film }}$ \\
\hline 12 & 129.8 & 0.991 & 0.75 & 23.47 & 0.395 & 0.43 \\
24 & 321.6 & 0.221 & 0.79 & 27.73 & 0.076 & 0.45 \\
36 & 735.2 & 0.068 & 0.81 & 58.45 & 0.016 & 0.48 \\
48 & 908.0 & 0.041 & 0.90 & 113.40 & 0.006 & 0.55 \\
\hline
\end{tabular}

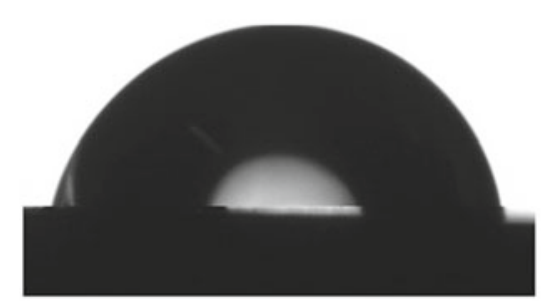

(a)

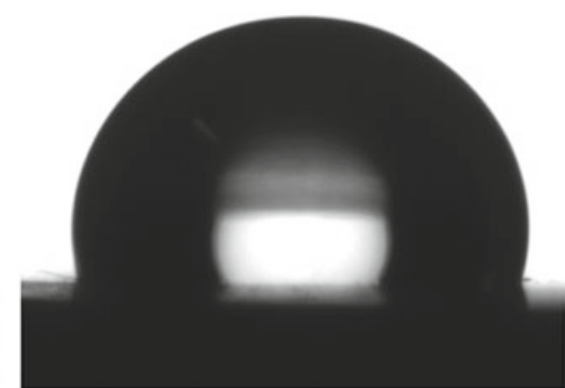

(b)

Figure 5. Contact angle images of (a) bare copper and (b) copper coated with OBI film.

and copper coated with OBI film. Contact angle values for bare copper and copper coated with OBI film are found to be $78^{\circ}$ and $109^{\circ}$, respectively. Contact angle values are sensitive to the orientation of molecules in the film. The OBI molecule gets chemisorbed on copper surface through the head group, namely benzimidazole. If the orientation of the molecule is such that the long hydrocarbon chain is normal or near normal to the surface and pointing outward, it reduces the access of water drop to the metal surface. Hence, the contact angle will be higher. Higher contact angle value for the copper coated with OBI indicates a high degree of hydrophobicity which is comparable to those of the films formed by 4-methylbenzenthiol (4-M-BT) and 4-acetamidobenzenethiol (4-AA-BT). ${ }^{12}$

3.2b X-ray photoelectron spectroscopic studies: The XPS survey spectrum of bare copper shows peaks corresponding to $\mathrm{Cu} 2 \mathrm{p}, \mathrm{C} 1 \mathrm{~s}$ and $\mathrm{O} 1$ s electrons. Computer deconvolution spectra for copper, carbon and oxygen are shown in figure $6(\mathrm{a}-\mathrm{c})$, respectively. The $\mathrm{Cu}$ $2 p_{3 / 2}$ peak at a binding energy of $932.6 \mathrm{eV}$ and $\mathrm{Cu} 2 \mathrm{p}_{1 / 2}$ peak at $952.4 \mathrm{eV}$ can be attributed to $\mathrm{Cu}$ (I). ${ }^{13}$ Binding energy of $\mathrm{C} 1 \mathrm{~s}$ electron at $285 \mathrm{eV}$ corresponds to contaminant carbon, which is likely due to cracking of 

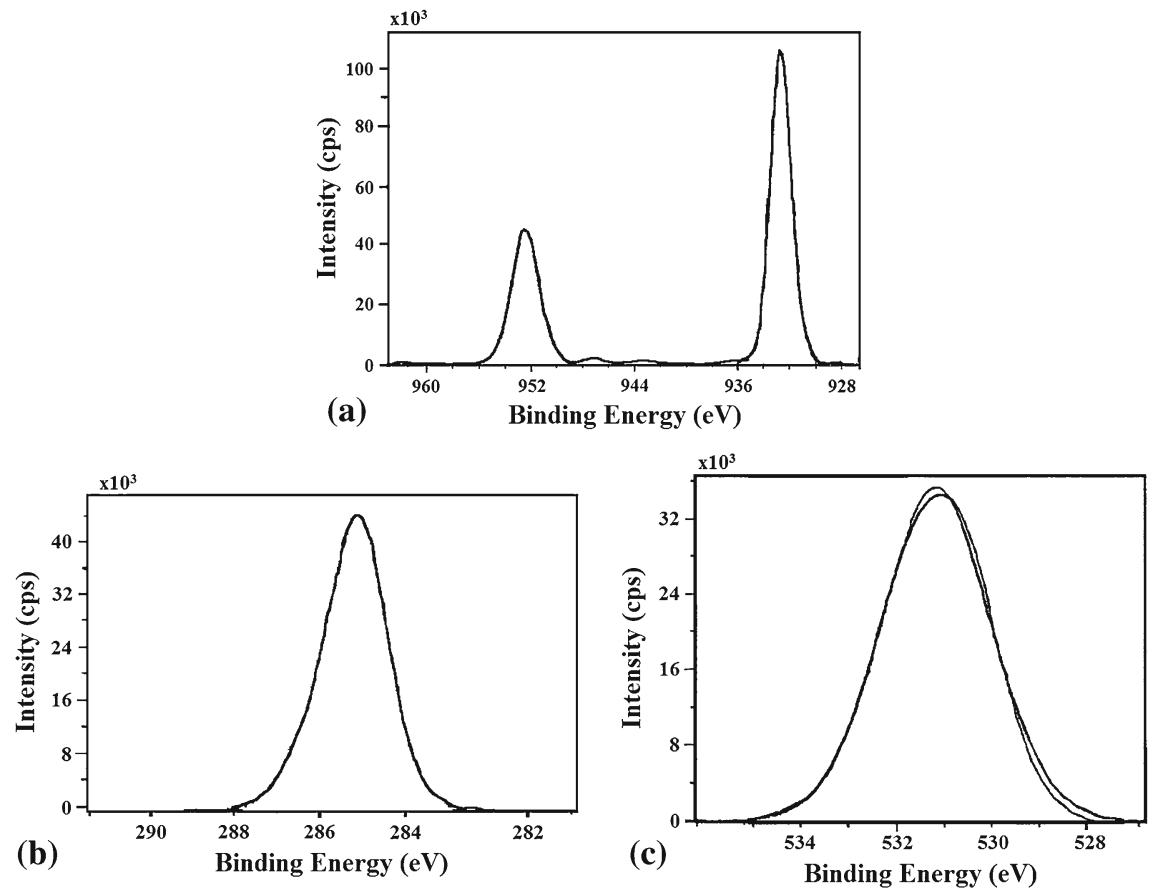

Figure 6. XPS deconvolution spectra of different elements present on the surface of bare copper (A-Cu 2p, B-C 1s, C-O 1s).
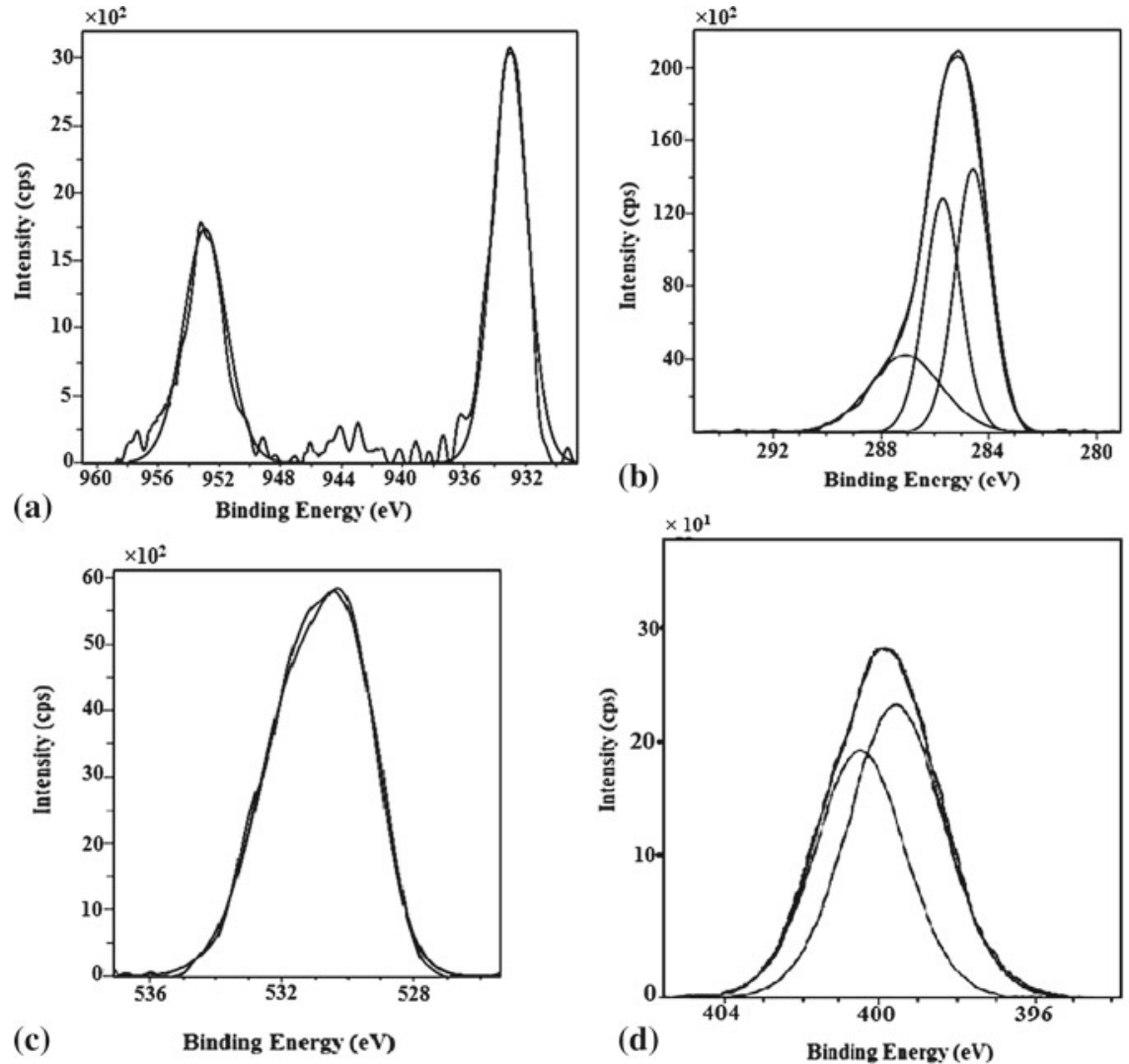

Figure 7. XPS deconvolution spectra of different elements present on the surface of copper coated with OBI film (A-Cu 2p, B-C 1s, C-O 1s, D-N 1s). 


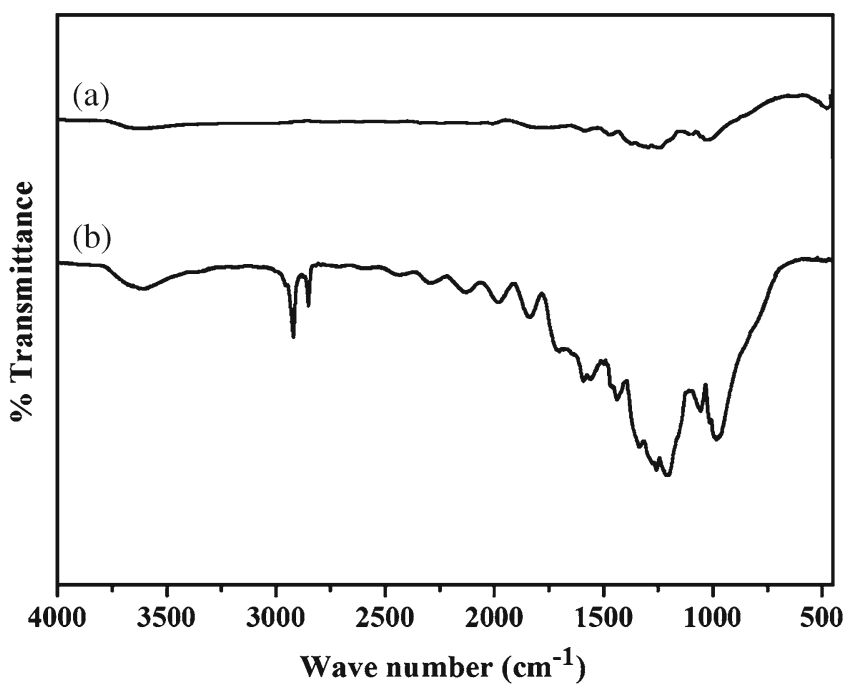

Figure 8. Reflection absorption FTIR spectra of (a) bare copper and (b) OBI-modified copper.

vacuum oil used in the XPS instrument. ${ }^{14}$ The $\mathrm{O} 1 \mathrm{~s}$ peak at $531.1 \mathrm{eV}$ is due to formation of $\mathrm{Cu}_{2} \mathrm{O}$ on copper surface, ${ }^{15,16}$ which is formed during the interval between polishing of the copper surface and XPS analysis.

In the XPS survey spectrum of copper surface coated with OBI film, peaks corresponding to $\mathrm{Cu} 2 \mathrm{p}, \mathrm{C} 1 \mathrm{~s}$, $\mathrm{O} 1 \mathrm{~s}$ and $\mathrm{N} 1 \mathrm{~s}$ are detected. Computer deconvolution spectra for copper, carbon, oxygen and nitrogen are shown in figure $7(\mathrm{a}-\mathrm{d})$, respectively. $\mathrm{Cu} 2 \mathrm{p}$ spectrum shows peaks of $\mathrm{Cu} 2 \mathrm{p}_{3 / 2}$ and $\mathrm{Cu} 2 \mathrm{p}_{1 / 2}$ at 933.0 and $952.9 \mathrm{eV}$, respectively, which are due to the initial oxidation of copper surface to $\mathrm{Cu}_{2} \mathrm{O}$ during film formation. It has been reported in literature that the $\mathrm{Cu} 2 \mathrm{p}_{3 / 2}$ peak around $933 \mathrm{eV}$ and the absence of shake-up satellites indicate the presence of cuprous copper, whereas the peak at $935 \mathrm{eV}$ and the presence of shake-up satellites indicate the presence of cupric copper. ${ }^{17}$ Therefore, it can be inferred that the peak observed in our studies at $933.0 \mathrm{eV}$ without any shake-up satellites is due to the presence of cuprous copper in the OBI film coated copper. The $\mathrm{O} 1 \mathrm{~s}$ spectrum shows a peak at $531.6 \mathrm{eV}$, which corresponds to oxygen of $\mathrm{Cu}_{2} \mathrm{O}$ formed on copper surface. $\mathrm{C} 1 \mathrm{~s}$ shows three peaks, one each at 284.6, 285.7 and $287.1 \mathrm{eV}$. The intense peak at $284.6 \mathrm{eV}$, is due to the presence of 18 carbon atoms in the alkyl chain of OBI. ${ }^{18,19}$ The $\mathrm{C} 1 \mathrm{~s}$ peak at $285.7 \mathrm{eV}$ arises due to the contaminated carbon, which is likely due to cracking of vacuum oil used in the XPS instrument. ${ }^{14}$ Another $\mathrm{C} 1 \mathrm{~s}$ peak at $287.1 \mathrm{eV}$ corresponds to the carbon atoms present in the benzimidazole ring. The peaks due to $\mathrm{N}$ 1s observed at 399.6 and $400.4 \mathrm{eV}$, respectively, are due to the presence of nitrogen atoms in OBI molecule in different chemical environments. The peak at $399.6 \mathrm{eV}$ arises due to nitrogen in the first position and the one at $400.4 \mathrm{eV}$ is attributed to nitrogen in the third position of the OBI molecule. This is because nitrogen in the third position will donate the electron pair easily to form a bond with copper surface. Therefore, electron density is less and the binding energy is shifted towards higher value $(400.4 \mathrm{eV})$. Whereas, for the nitrogen in first position having long alkyl chain, it is difficult to form a bond with copper surface. Therefore, electron density is relatively high and binding energy is relatively less $(399.6 \mathrm{eV})$. Characteristic binding energy of elemental nitrogen was reported to be $398.0 \mathrm{eV}$ in literature. ${ }^{20}$ Positive shift in N1s binding energies from elemental binding energy reveals that nitrogen atoms present in OBI molecule play a vital role in complex formation between cuprous copper and OBI. ${ }^{14}$
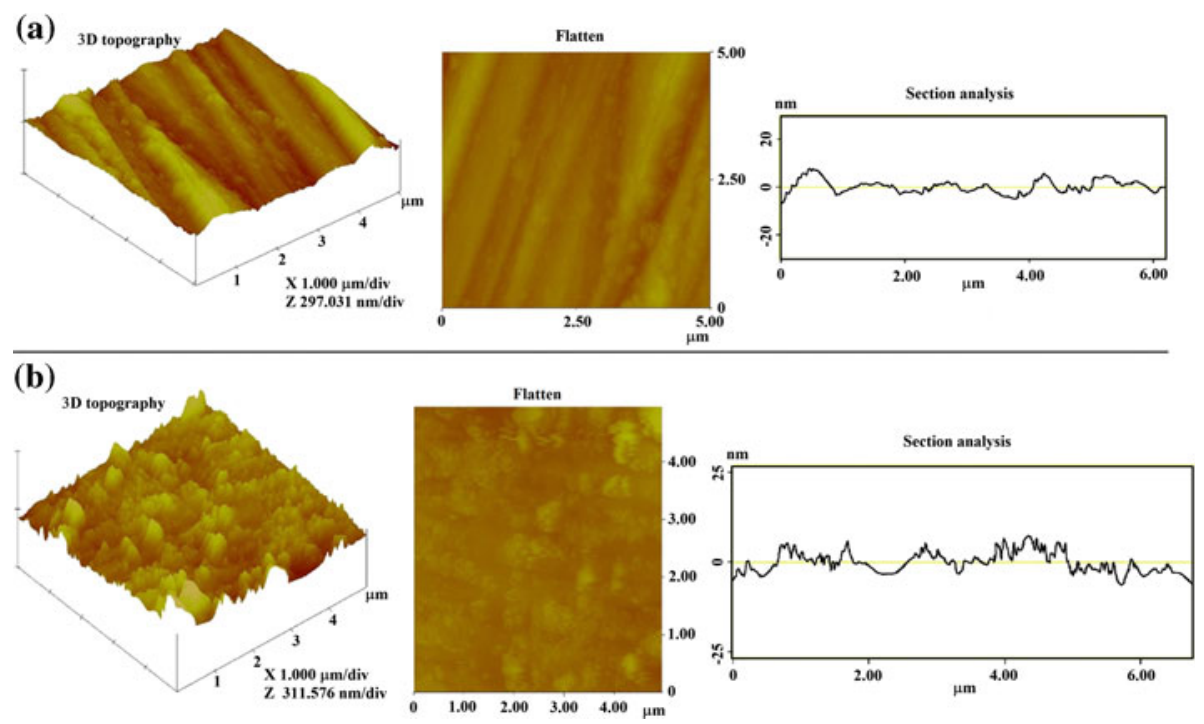

Figure 9. AFM images of (a) bare copper and (b) copper coated with OBI film. 

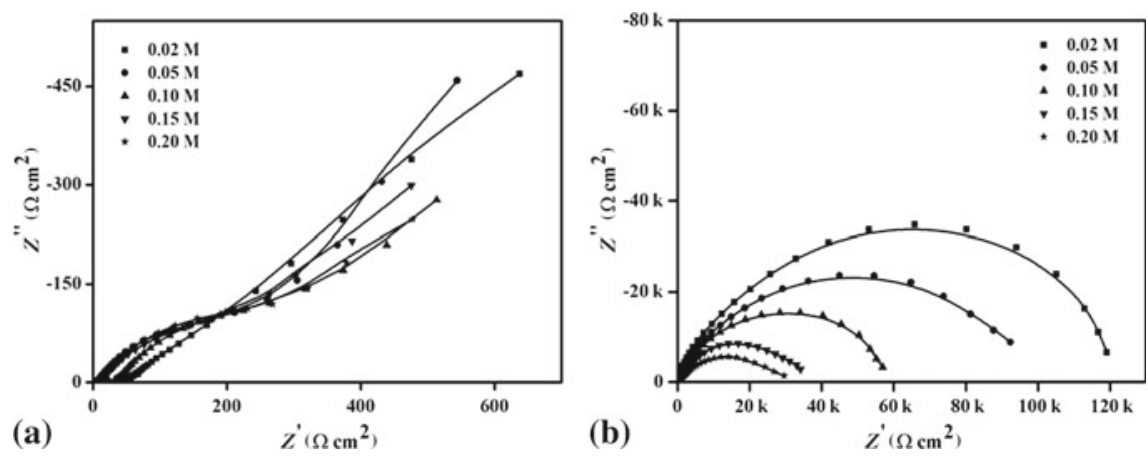

Figure 10. Nyquist plots of (a) bare copper and (b) copper coated with OBI film in different concentrations of $\mathrm{HCl}$. (Immersion period: $1 \mathrm{~h}$, temperature: $30 \pm$ $0.1^{\circ} \mathrm{C}$.)

3.2c Reflection absorption FTIR spectral studies: Reflection absorption FTIR spectra for bare copper and the copper coated with OBI film are shown in figure 8(a) and (b), respectively. Spectrum of OBImodified copper shows two bands, one at $2852 \mathrm{~cm}^{-1}$ and the other at $2920 \mathrm{~cm}^{-1}$, which are due to $\mathrm{CH}_{2}$ symmetric stretch and asymmetric stretch modes, respectively. Mekhalif et al. reported a comparative assessment of n-dodecanethiol and n-dodecaneselenol monolayers on electroplated copper. They attributed the two bands at $2851 \mathrm{~cm}^{-1}$ and $2922 \mathrm{~cm}^{-1}$ observed in reflection absorption IR spectra to the $\mathrm{CH}_{2}$ symmetric stretch and asymmetric stretch modes respectively. ${ }^{21}$ Yoshida and Ishida studied FTIR reflection absorption spectrum of undecylimidazole on copper surface. They obtained two bands at 2853 and $2925 \mathrm{~cm}^{-1}$ and attributed them to $\mathrm{CH}_{2}$ symmetric stretching and asymmetric stretching modes, respectively. ${ }^{22}$ Thus, there is a clear evidence of presence of aliphatic hydrocarbon chain in the film of OBI on copper. The FTIR reflection absorption spectrum of OBI film also shows the appearance of $\mathrm{C}=\mathrm{C}$ stretching band at $1570 \mathrm{~cm}^{-1}$, $\mathrm{C}=\mathrm{N}$ stretching band at $1440 \mathrm{~cm}^{-1}$ and $\mathrm{C}-\mathrm{N}$ stretching band at $1261 \mathrm{~cm}^{-1}$. These peaks infer the presence of OBI on the copper surface. Lowering of characteristic $\mathrm{C}=\mathrm{N}$ stretching band from 1600 to $1440 \mathrm{~cm}^{-1}$ infers the formation of a complex between OBI and cuprous ions through nitrogen atoms. ${ }^{23}$

3.2d Atomic force microscopy: Surface morphologies of polished copper and copper coated with OBI film are investigated by AFM technique. Figure 9(a) and (b) shows AFM images such as 3D-topography, flatten and section analysis of the polished copper surface and copper surface coated with OBI film, respectively. Root mean square (rms) roughness analysis was carried out for both polished copper and copper coated with OBI film. Vertical lines in the polished copper sample are due to fine scratches obtained during polishing process. ${ }^{24}$ These polishing scratches result in an rms roughness of $17.275 \mathrm{~nm}$. The AFM image of copper surface coated with OBI shows a film of OBI and there is a reduction in the rms roughness to $13.710 \mathrm{~nm}$. A uniform variation of thickness in section analysis also indicates homogeneity of the OBI film.
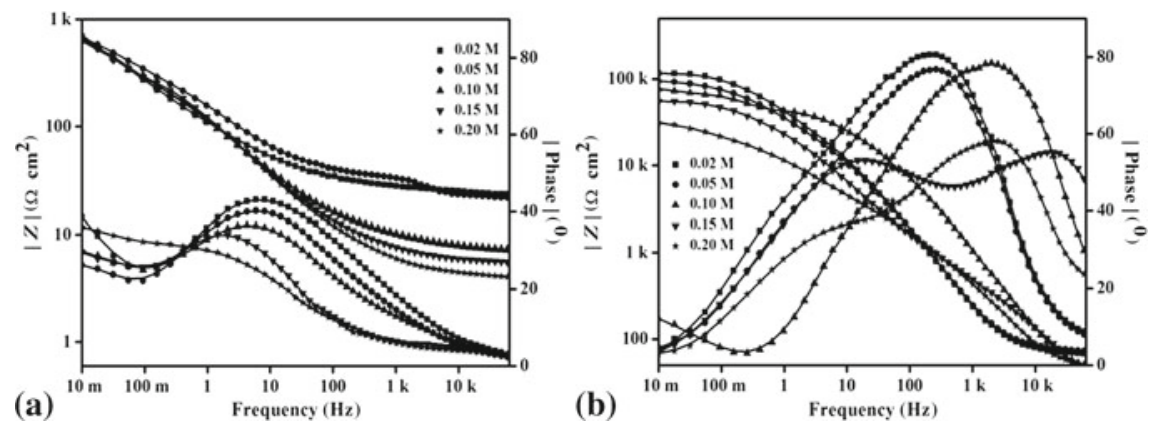

Figure 11. Bode plots of (a) bare copper and (b) copper coated with OBI film in different concentrations of $\mathrm{HCl}$. (Immersion period: $1 \mathrm{~h}$, temperature: $30 \pm 0.1^{\circ} \mathrm{C}$.) 
Table 3. Impedance parameters of bare copper and copper coated with $\mathrm{OBI}$ film in $\mathrm{HCl}$ environment at different concentrations. (Immersion period: $1 \mathrm{~h}$, temperature: $30 \pm 0.1^{\circ} \mathrm{C}$.)

\begin{tabular}{lcccccccc}
\hline Specimen & $\begin{array}{c}\text { Conc. } \\
(\mathrm{M})\end{array}$ & $\begin{array}{c}R_{\mathrm{ct}} \\
\left(\mathrm{k} \Omega \mathrm{cm}^{2}\right)\end{array}$ & $\begin{array}{c}\mathrm{CPE} \\
\left(\mu \mathrm{F} \mathrm{cm}^{-2}\right)\end{array}$ & $n$ & $\begin{array}{c}R_{\text {film }} \\
\left(\mathrm{k} \Omega \mathrm{cm}^{2}\right)\end{array}$ & $\begin{array}{c}\mathrm{CPE}_{\text {film }} \\
\left.(\mu \mathrm{F} \mathrm{cm})^{-2}\right)\end{array}$ & $n_{\text {film }}$ & $\mathrm{IE}(\%)$ \\
\hline Bare copper & 0.02 & 0.54 & 18.66 & 0.54 & - & - & - & - \\
Copper with OBI film & 0.02 & 101.76 & 0.66 & 0.91 & 18.35 & 0.248 & 0.64 & 99.5 \\
Bare copper & 0.05 & 0.53 & 32.15 & 0.54 & - & - & - & - \\
Copper with OBI film & 0.05 & 75.43 & 0.64 & 0.90 & 15.06 & 0.293 & 0.63 & 99.3 \\
Bare copper & 0.10 & 0.51 & 48.91 & 0.53 & - & - & - & - \\
Copper with OBI film & 0.10 & 55.94 & 0.73 & 0.81 & 13.05 & 0.356 & 0.64 & 99.1 \\
Bare copper & 0.15 & 0.42 & 62.47 & 0.53 & - & - & - & - \\
Copper with OBI film & 0.15 & 32.76 & 0.78 & 0.79 & 10.12 & 0.487 & 0.63 & 98.7 \\
Bare copper & 0.20 & 0.35 & 65.55 & 0.50 & - & - & - & - \\
Copper with OBI film & 0.20 & 26.05 & 0.84 & 0.77 & 7.11 & 0.640 & 0.70 & 98.6 \\
\hline
\end{tabular}

\subsection{Corrosion protection of copper by OBI film}

3.3a Electrochemical impedance studies: Impedance studies of bare copper and copper electrodes coated with OBI film were carried out in aqueous $\mathrm{HCl}$ solution after $1 \mathrm{~h}$ immersion, since the open circuit potential became stable within $1 \mathrm{~h}$. Figure $10(\mathrm{a})$ and (b) shows Nyquist plots of bare copper and OBI-modified copper, respectively, in different concentrations (0.02$0.20 \mathrm{M}$ ) of $\mathrm{HCl}$, at a constant temperature of $30 \pm$ $0.1^{\circ} \mathrm{C}$. Corresponding Bode plots are shown in figure 11(a) and (b). Impedance parameters obtained from these results are shown in table 3. The EIS data of bare copper in $\mathrm{HCl}$ solution are best fitted by using the equivalent circuit shown in figure 12, whereas for the copper electrode coated with OBI film, the EIS data are best fitted with the equivalent circuit shown in figure 3(b).

Nyquist plots of bare copper in aq. $\mathrm{HCl}$ solution display a small semicircle at higher frequencies and a straight line at lower frequencies. Low frequency straight line, i.e., the Warburg impedance, is due to diffusion of oxygen to the copper surface. ${ }^{25}$ Nyquist plots of OBI film coated copper electrodes are quite different from those of bare copper electrode. After the formation of film on the copper electrode, the Warburg impedance

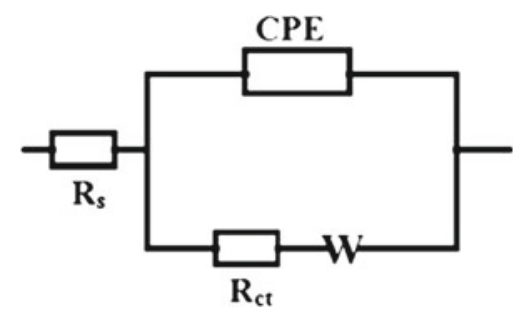

Figure 12. Equivalent circuit used in impedance measurements of bare copper. disappeared and semicircles with much higher diameter are observed. The large semicircle observed from high to low frequency region indicates that charge transfer resistance becomes dominant in the corrosion process due to the formation of a protective OBI film on copper surface.

In $0.02 \mathrm{M} \mathrm{HCl}$ solution, the Bode plot of bare copper exhibits a phase angle maximum of $40^{\circ}$, whereas, in the case of OBI-modified copper, the phase angle maximum is increased to $81^{\circ}$ and is shifted towards higher frequency side. Total impedance value is increased to a much higher value after film formation. At all the studied concentrations, phase angle maxima are higher in the case of OBI-modified copper when compared with bare copper. The CPE values are decreased, the $n$ values are increased and $R_{\mathrm{ct}}$ values are enormously increased in the presence of OBI film on the copper surface. For example, in $0.02 \mathrm{M} \mathrm{HCl}$ environment, the $R_{\text {ct }}$ value is increased from $0.54 \mathrm{k} \Omega \mathrm{cm}^{2}$ in case of bare copper to $101.76 \mathrm{k} \Omega \mathrm{cm}^{2}$ for copper coated with OBI film in the same environment. The CPE value decreased from 18.66 to $0.66 \mu \mathrm{F} \mathrm{cm} \mathrm{cm}^{-2}$ and $n$ value increased from 0.54 to 0.91 . Increase in $n$ value indicates that the surface becomes smooth after the formation of OBI film. Inhibition efficiencies are found to be in the range of $99.5 \%$ to $98.6 \%$ within the studied concentration range.

Figure 13(a) and (b) shows Nyquist plots of bare copper and OBI film coated copper in $0.02 \mathrm{M} \mathrm{HCl}$ solution at different immersion periods (1-24h). Corresponding Bode plots are shown in figure 14(a) and (b). Impedance parameters obtained from these results are shown in table 4 . The $R_{\mathrm{ct}}$ values of OBI-modified copper are much higher than those of bare copper at all immersion periods. Phase angle maxima are merged at all immersion periods and value of $n$ at various immersion periods has not changed much. This shows that 

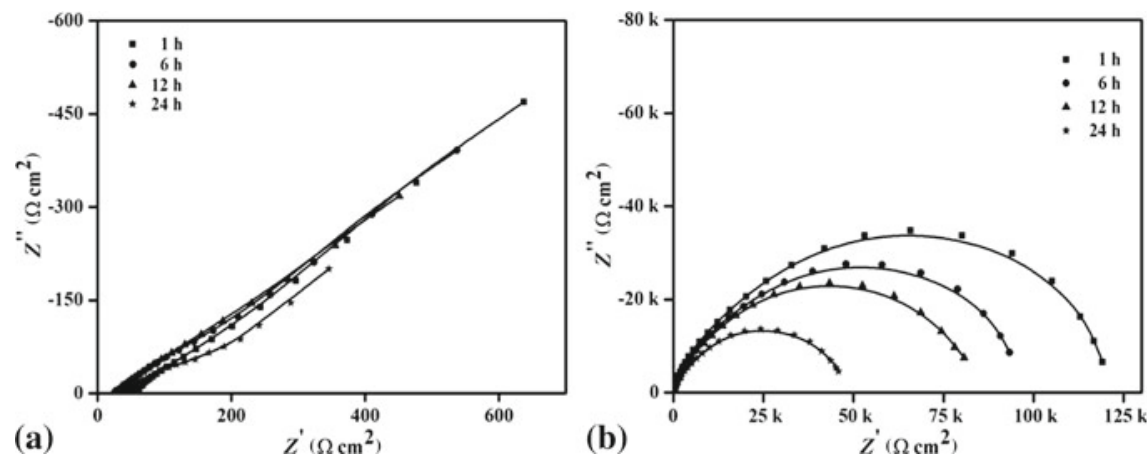

Figure 13. Nyquist plots of (a) bare copper and (b) copper coated with OBI film in $0.02 \mathrm{M} \mathrm{HCl}$ at different immersion periods (temperature: $30 \pm 0.1^{\circ} \mathrm{C}$ ).
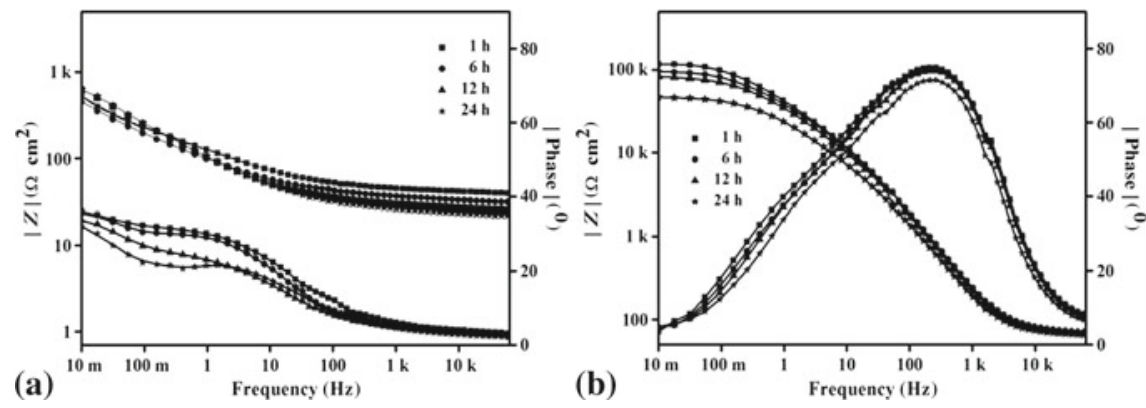

Figure 14. Bode plots of (a) bare copper and (b) copper coated with OBI film in $0.02 \mathrm{M} \mathrm{HCl}$ at different immersion periods (temperature: $30 \pm 0.1^{\circ} \mathrm{C}$ ).

Table 4. Impedance parameters of bare copper and copper coated with OBI film in $0.02 \mathrm{M} \mathrm{HCl}$ environment at different immersion periods (temperature: $30 \pm 0.1^{\circ} \mathrm{C}$ ).

\begin{tabular}{lcrrccccc}
\hline Specimen & $\begin{array}{c}\text { Immersion } \\
\text { time (h) }\end{array}$ & $\begin{array}{c}R_{\mathrm{ct}} \\
\left(\mathrm{k} \Omega \mathrm{cm}^{2}\right)\end{array}$ & $\begin{array}{c}\mathrm{CPE} \\
\left(\mu \mathrm{F} \mathrm{cm}^{-2}\right)\end{array}$ & $n$ & $\begin{array}{c}R_{\text {film }} \\
\left(\mathrm{k} \Omega \mathrm{cm}^{2}\right)\end{array}$ & $\begin{array}{c}\mathrm{CPE}_{\text {film }} \\
\left(\mu \mathrm{F} \mathrm{cm}^{-2}\right)\end{array}$ & $n_{\text {film }}$ & $\mathrm{IE} \mathrm{( \% )}$ \\
\hline Bare copper & 1 & 0.54 & 18.66 & 0.54 & - & - & - & - \\
Copper with OBI film & 1 & 101.76 & 0.66 & 0.91 & 18.35 & 0.248 & 0.64 & 99.5 \\
Bare copper & 6 & 0.51 & 29.43 & 0.51 & - & - & - & - \\
Copper with OBI film & 6 & 81.82 & 0.65 & 0.91 & 16.39 & 0.261 & 0.63 & 99.4 \\
Bare copper & 12 & 0.49 & 30.35 & 0.42 & - & - & - & - \\
Copper with OBI film & 12 & 69.94 & 0.72 & 0.91 & 13.14 & 0.284 & 0.63 & 99.3 \\
Bare copper & 24 & 0.48 & 42.15 & 0.34 & - & - & - & - \\
Copper with OBI film & 24 & 41.43 & 0.88 & 0.90 & 7.60 & 0.314 & 0.60 & 98.8 \\
\hline
\end{tabular}

homogeneity of the protective film is maintained even after an immersion period of $24 \mathrm{~h}$. Inhibition efficiencies are in the range of $99.5 \%$ to $98.8 \%$ in $0.02 \mathrm{M}$ $\mathrm{HCl}$ environment within the range of studied immersion times.

3.3b Potentiodynamic polarization studies: Potentiodynamic polarization curves for bare copper and OBI-modified copper in aq. $\mathrm{HCl}$ solution at different concentrations $(0.02-0.2 \mathrm{M})$ after an immersion period of $1 \mathrm{~h}$ are shown in figure 15(a) and (b), respectively. Corresponding corrosion parameters such as corrosion potential $\left(E_{\text {corr }}\right)$, corrosion current density $\left(j_{\text {corr }}\right)$, cathodic Tafel slope $\left(b_{\mathrm{c}}\right)$ and anodic Tafel slope $\left(b_{\mathrm{a}}\right)$ are obtained by the extrapolation of Tafel curves and are given in table 5 . At all the concentrations, $j_{\text {corr }}$ values of OBI-modified copper are seen to reduce significantly, when compared with bare copper. For example, in $0.02 \mathrm{M} \mathrm{HCl}$ solution, the bare copper electrode 

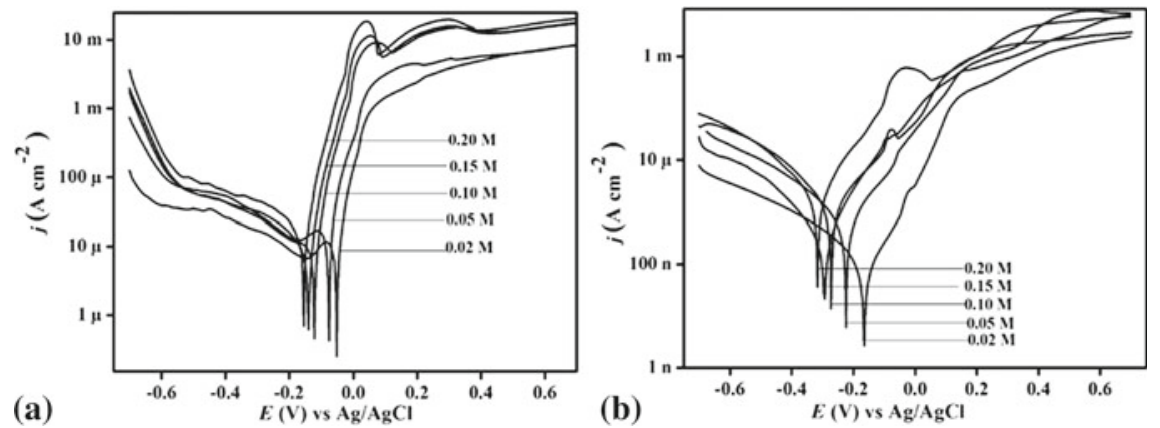

Figure 15. Potentiodynamic polarization curves of (a) bare copper and (b) copper coated with OBI film in different concentrations of $\mathrm{HCl}$. (Immersion period: $1 \mathrm{~h}$, temperature: $30 \pm 0.1^{\circ} \mathrm{C}$.)

shows corrosion current density value of $8.87 \mu \mathrm{A} \mathrm{cm}^{-2}$, whereas the OBI-coated copper shows $0.037 \mu \mathrm{A} \mathrm{cm}^{-2}$. Corrosion potential is shifted towards negative side after the formation of OBI film on copper surface. Cathodic Tafel slope $\left(b_{c}\right)$ is shifted to a greater extent than the anodic Tafel slope $\left(b_{\mathrm{a}}\right)$ after formation of OBI film on copper surface. For example, in $0.02 \mathrm{M} \mathrm{HCl}$, the $b_{\mathrm{c}}$ value is shifted from -166.2 to $-73.6 \mathrm{mV} \mathrm{dec}{ }^{-1}$, whereas $b_{\mathrm{a}}$ value is shifted from 59.8 to $65 \mathrm{mV} \mathrm{dec}^{-1}$ only. From these observations, it is inferred that cathodic reaction of corrosion process is controlled more effectively by the OBI film on copper surface in $\mathrm{HCl}$ solutions. Corrosion inhibition efficiencies are calculated from $j_{\text {corr }}$ values and are found to be in the range of $99.6 \%$ to $97.4 \%$ within the studied concentration range. These results are in agreement with those obtained from electrochemical impedance studies.

3.3c Cyclic voltammetric studies: Figure 16(a) and (b) shows cyclic voltammograms of bare copper and copper coated with OBI film for two cycles at different sweep rates of 30,60 and $120 \mathrm{mV} \mathrm{s}^{-1}$. For both bare copper and copper coated with OBI film, in forward sweep, only one anodic peak is observed and in the reverse sweep also only one cathodic peak is observed. Studies reported in literature, ${ }^{26,27}$ showed that at lower concentrations and higher sweep rates, only a single peak due to oxidation of $\mathrm{Cu}$ to $\mathrm{Cu}^{2+}$ in the anodic direction and single cathodic peak due to reduction of $\mathrm{Cu}^{2+}$ to $\mathrm{Cu}$ were observed in the studied potential range. With increase in sweep rates from 30 to $120 \mathrm{mV} \mathrm{s}^{-1}$, anodic and cathodic peak currents of OBI film coated copper are slightly increased and peak currents are very less when compared with bare copper. For example, at $30 \mathrm{mV} \mathrm{s}^{-1}$, anodic peak current decreased from $4.4 \mathrm{~mA} \mathrm{~cm}^{-2}$ to $36.1 \mu \mathrm{A} \mathrm{cm}^{-2}$ and cathodic current decreased from $3.3 \mathrm{~mA} \mathrm{~cm}^{-2}$ to $35.3 \mu \mathrm{Acm}^{-2}$ when copper surface was modified with OBI film. Figure 17(a) and (b) shows cyclic voltammograms of bare copper and OBI film coated copper for 15 cycles at a constant sweep rate of $30 \mathrm{mV} \mathrm{s}^{-1}$. Even when number of cycles is increased to 15 , increase in both anodic and cathodic peak currents is not significant. This result

Table 5. Corrosion parameters obtained by potentiodynamic polarization studies of bare copper and copper coated with $\mathrm{OBI}$ film in $\mathrm{HCl}$ environment at different concentrations. (Immersion period: $1 \mathrm{~h}$, temperature: $30 \pm 0.1^{\circ} \mathrm{C}$.)

\begin{tabular}{lcccccc}
\hline Specimen & $\begin{array}{c}\text { Conc. } \\
(\mathrm{M})\end{array}$ & $\begin{array}{c}E_{\text {corr }} \\
(\mathrm{mV})\end{array}$ & $\begin{array}{c}j_{\text {corr }} \\
\left(\mu \mathrm{A} \mathrm{cm}{ }^{-2}\right)\end{array}$ & $\begin{array}{c}b_{\mathrm{a}} \\
\left(\mathrm{mV} \mathrm{dec}^{-1}\right)\end{array}$ & $\begin{array}{c}b_{\mathrm{c}} \\
\left(\mathrm{mV} \mathrm{dec}^{-1}\right)\end{array}$ & $\mathrm{IE} \mathrm{( \% )}$ \\
\hline Bare copper & 0.02 & -54.7 & 8.870 & 59.8 & -166.2 & - \\
Copper with OBI film & 0.02 & -163.8 & 0.037 & 65.0 & -73.6 & 99.6 \\
Bare copper & 0.05 & -75.2 & 11.723 & 65.2 & -148.1 & - \\
Copper with OBI film & 0.05 & -218.1 & 0.126 & 51.3 & -87.0 & 98.9 \\
Bare copper & 0.10 & -115.5 & 17.154 & 60.6 & -318.2 & - \\
Copper with OBI film & 0.10 & -251.3 & 0.229 & 47.0 & -25.6 & 98.7 \\
Bare copper & 0.15 & -134.5 & 18.014 & 61.5 & -167.8 & - \\
Copper with OBI film & 0.15 & -274.7 & 0.367 & 58.5 & -44.4 & 98.0 \\
Bare copper & 0.20 & -142.7 & 21.197 & 75.8 & -289.3 & - \\
Copper with OBI film & 0.20 & -296.1 & 0.550 & 86.0 & -121.0 & 97.4 \\
\hline
\end{tabular}



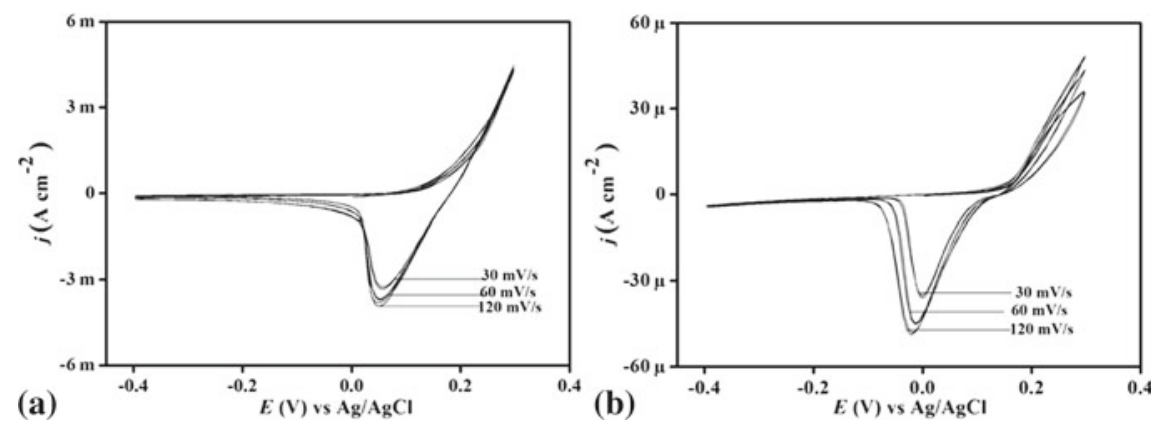

Figure 16. Cyclic voltammograms in $0.02 \mathrm{M} \mathrm{HCl}$ after $1 \mathrm{~h}$ immersion at different sweep rates: (a) bare copper and (b) copper coated with OBI film.

infers the stability of OBI film. Thus, CV studies also provide evidence that $\mathrm{OBI}$ film protects copper from corrosion in $\mathrm{HCl}$ environment.

3.3d Gravimetric measurements: After an immersion period of 10 days in $0.02 \mathrm{M} \mathrm{HCl}$ environment, corrosion rates of $0.2425 \mathrm{mmpy}$ for bare copper and of $0.0165 \mathrm{mmpy}$ for copper coated with OBI film are obtained. An inhibition efficiency of $95.8 \%$ is obtained from the data. These results show that the corrosion protection of copper by $\mathrm{OBI}$ film is excellent in $\mathrm{HCl}$ environment.

3.3e Scanning electron microscopic studies: Scanning electron micrographs of bare copper and copper coated with OBI film are obtained after immersion in $0.02 \mathrm{M} \mathrm{HCl}$ for a period of 10 days and are shown in figure 18(a) and (b). The SEM image of bare copper clearly shows that the surface is severely damaged due to dissolution of copper in aggressive solution. However, in the case of copper coated with OBI film, we can see that the surface consists of compact and ordered layer-like structure without any corrosion products.

\subsection{Mechanism of corrosion protection by OBI film}

In the absence of OBI film, anodic dissolution of copper in $\mathrm{HCl}$ environment proceeds via a two-step oxidation process. ${ }^{14}$

$$
\mathrm{Cu}+\mathrm{Cl}^{-} \longrightarrow \mathrm{CuCl}+\mathrm{e}^{-}
$$

The $\mathrm{CuCl}$ has poor adhesion and is unable to protect the copper surface and transforms into the soluble cuprous chloride complex, $\mathrm{CuCl}_{2}^{-}$as shown in eq. (2). ${ }^{28}$

$$
\mathrm{CuCl}+\mathrm{Cl}^{-} \longrightarrow \mathrm{CuCl}_{2}^{-} \text {. }
$$

Dissolution of $\mathrm{CuCl}_{2}^{-}$complex occurs as per the reaction shown in eq. (3). ${ }^{29}$

$$
\mathrm{CuCl}_{2}^{-} \longrightarrow \mathrm{Cu}^{2+}+2 \mathrm{Cl}^{-}+\mathrm{e}^{-} \text {. }
$$

Cathodic reaction involves reduction of oxygen and hydrogen ions as per the eq. (4).

$$
4 \mathrm{H}^{+}+4 \mathrm{e}^{-}+\mathrm{O}_{2} \longrightarrow 2 \mathrm{H}_{2} \mathrm{O} \text {. }
$$
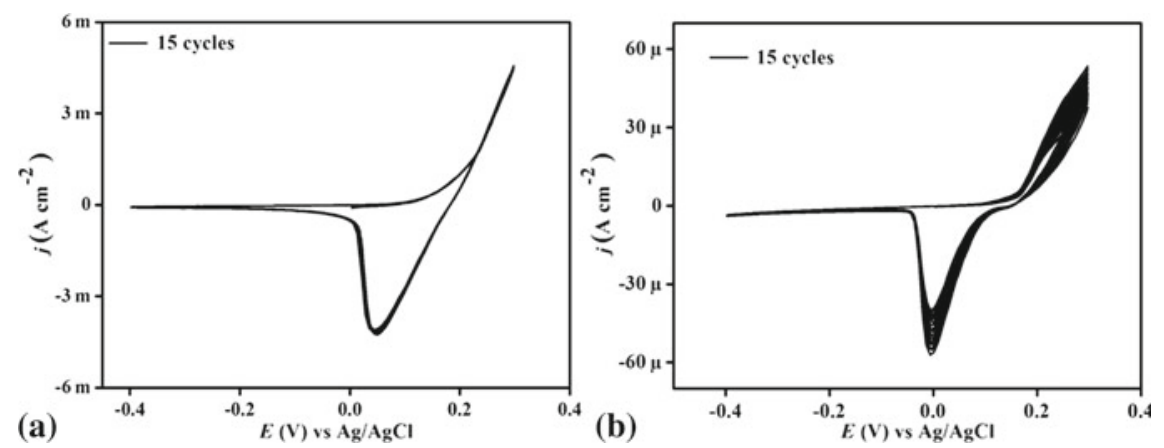

Figure 17. Cyclic voltammograms in $0.02 \mathrm{M} \mathrm{HCl}$ after $1 \mathrm{~h}$ immersion for 15 cycles at $30 \mathrm{mV} \mathrm{s}^{-1}$; (a) bare copper and (b) copper coated with OBI film. 


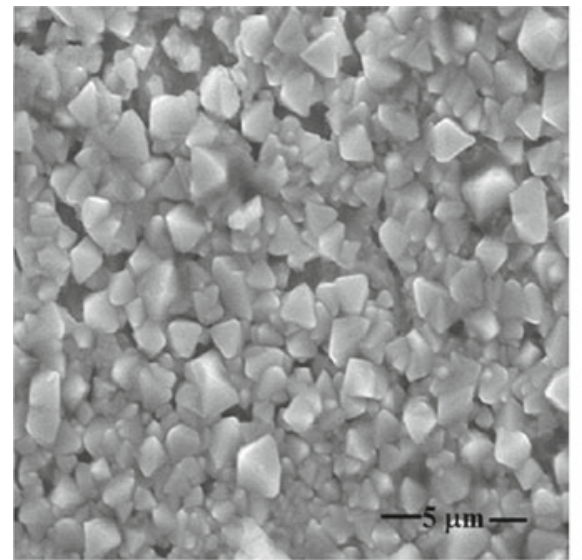

(a)

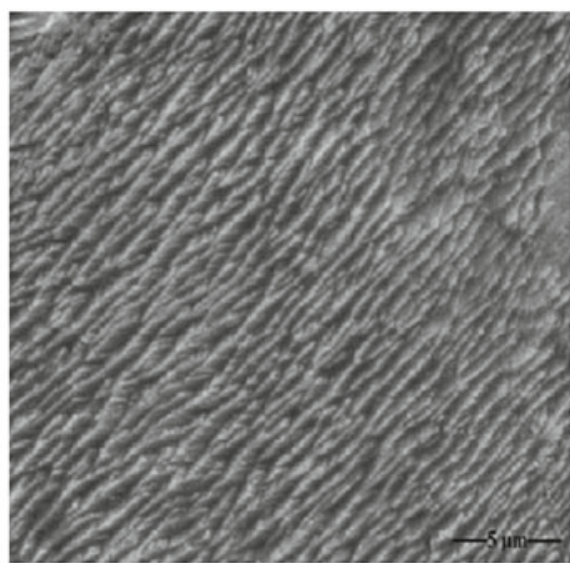

(b)

Figure 18. SEM images after 10 days immersion in $0.02 \mathrm{M} \mathrm{HCl}$; (a) bare copper and (b) copper coated with OBI film.

Overall corrosion reaction of copper in acidic chloride solution is given in eq. (5).

$$
2 \mathrm{Cu}+4 \mathrm{HCl}+\mathrm{O}_{2} \longrightarrow 2 \mathrm{Cu}^{2+}+4 \mathrm{Cl}^{-}+2 \mathrm{H}_{2} \mathrm{O} \text {. }
$$

A plausible mechanism for corrosion protection of copper by OBI film is shown in figure 19. The explanation is as follows. Relatively higher contact angle value of OBI film reveals hydrophobic nature, which is due to orientation of long alkyl chain of OBI away from the copper surface. Chemisorption of OBI molecules on the copper surface takes place through nitrogen atoms, which form co-ordinate bonds with unoccupied d-orbital of $\mathrm{Cu}^{+}$ions available due to initial oxidation of copper. $\mathrm{Cu}^{+}$ions are known to form bidentate complexes with ligands. In addition to strong co-ordinate linkages between $\mathrm{Cu}^{+}$and $\mathrm{N}$, there are non-covalent interactions such as Vanderwaal interactions between long alkyl chains and $\pi$-stack interactions between benzimidazole rings, which result in formation of a dense and defect-free film on copper surface. Thus, there is

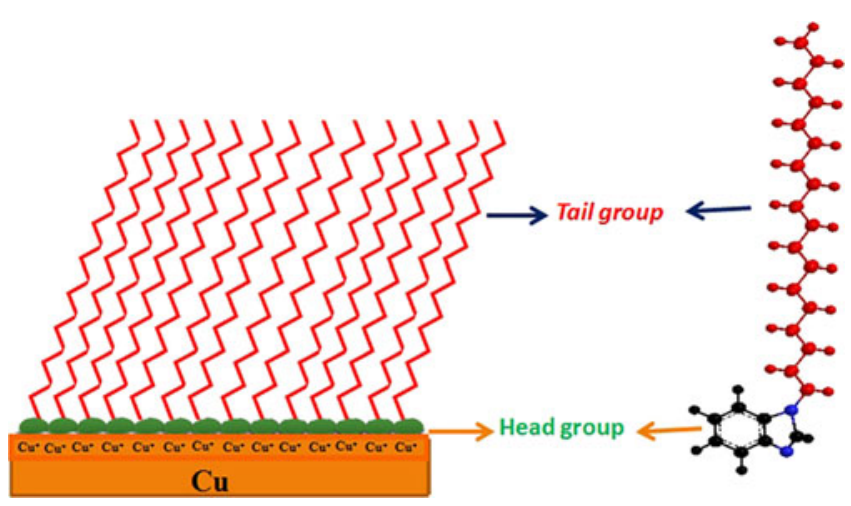

Figure 19. Schematic illustration of formation of protective film by OBI on copper surface. formation of a $\left[\mathrm{Cu}^{+}-\mathrm{OBI}\right]$ complex on copper surface, which is highly protective in nature.

\section{Conclusion}

Optimum conditions for the formation of OBI film on copper surface are established. These include methanol as solvent, $5 \mathrm{mM}$ concentration of OBI and $48 \mathrm{~h}$ immersion period. SEM and AFM studies confirm the complete coverage of OBI molecules on the copper surface. XPS and reflection absorption FTIR spectra inferred that the OBI molecules form chelated complexes with $\mathrm{Cu}$ (I) on copper surface. Contact angle measurements reveal the hydrophobic nature of OBI film. Selfassembled films of OBI effectively protect copper from corrosion in $\mathrm{HCl}$ solution within the studied concentration range and immersion period. Inhibition efficiencies obtained from gravimetric studies, electrochemical impedance studies and polarization studies are in excellent agreement with each other. Polarization studies inferred that OBI film functions as a cathodic inhibitor. Cyclic voltammetric studies showed that OBI film is stable even after 15 cycles, when the electrode is polarized to an anodic potential of $0.35 \mathrm{~V}$ vs. $\mathrm{Ag} / \mathrm{AgCl}$ $(3 \mathrm{M} \mathrm{KCl})$.

\section{Acknowledgement}

The authors are thankful to the National Institute of Technology Warangal, Andhra Pradesh, India, for providing necessary facilities for carrying out this research.

\section{References}

1. Ho H M, Lam W, Stoukatch S, Ratchev P, Vath III CJ and Beyne E 2003 Microelectron. Reliab. 43913 
2. Gracias D H, Method to increase electromigration resistance of copper using self-assembled organic thiolate monolayers. 2005 U.S. Patent 6858527

3. Appa Rao B V, Yakub Iqbal Md and Sreedhar B 2009 Corros. Sci. $\mathbf{5 1} 1441$

4. Appa Rao B V, Yakub Iqbal Md and Sreedhar B 2010 Electrochim. Acta 55620

5. Laibinis P E and Whitesides G M 1992 J. Am. Chem. Soc. 1149022

6. Quan Z, Wu X, Chen S, Zhao S and Ma H 2001 Corrosion 57195

7. Chen H, Ren H Y, Zong Y W, Qun J X and Guo D Z 2008 Corros. Sci. 503527

8. Stupnisek-Lisac E, Gazivoda A and Madzarac M 2002 Electrochim. Acta 474189

9. Otmacic H and Stupnisek L E 2003 Electrochim. Acta 48985

10. Nezhada A K, Zareb A, Parhami A, Soltani Rod M N and Nejabat J R 2007 J. Iran. Chem. Soc. 4271

11. Freeman R A and Silverman, D C 1992 Corrosion 48 463

12. Tan Y S, Srinivasan M P, Pehkonen S O and Simonchooi Y M 2006 Corros. Sci. 48840

13. Wang $\mathrm{C}$ T, Chen S H, Ma H Y, Hua L and Wang N X 2002 J. Serb. Chem. Soc. 67685

14. Cicileo G P, Rosales B M, Varela F E and Vilche J R 1999 Corros. Sci. 411359
15. Ye X R, Xin X Q, Zhu J J and Xue Z L 1998 Appl. Surf. Sci. 135307

16. Petkova G, Sokolova E, Raicheva S and Ivanov P 1998 J. Appl. Electrochem. 281067

17. Kamdem D P, Zhang J and Adnot A 2001 Holzforschung 5516

18. Taneichi D, Haneda R and Aramaki K 2001 Corros. Sci. 431589

19. Hutt D A and Liu C 2005 Appl. Surf. Sci. 252400

20. Beccaria A M and Bertolotto C 1997 Electrochim. Acta 421361

21. Mekhalif Z, Fonder G, Laffineur F and Delhalle J 2008 J. Electroanal. Chem. $\mathbf{6 2 1} 245$

22. Yoshida S and Ishida H 1995 Appl. Surf. Sci. 8939

23. Baba H, Kodama T, Mori K and Hirahara H 1997 Corros. Sci. 39555

24. Kleber C, Hilfrich U and Schreiner M 2007 Appl. Surf. Sci. 2533712

25. Ma H, Chen S, Niu L, Zhao S, Li S and Li D $2002 J$. Appl. Electrochem. 3265

26. Fonsati M, Zucchi F and Trabanelli G 1998 Electrochim. Acta 44311

27. Marconato J C, Bulhoes L O and Temperini M L 1998 Electrochim. Acta. $\mathbf{4 3} 771$

28. Yan C W, Lin H C and Cao C N 2000 Electrochim. Acta 452815

29. Crundwell F K 1992 Electrochim. Acta 372707 